\title{
психоонкология
}

\author{
УДК 616.891.6:616.895.4-055.2:616.411-006.6:591.477.36:615.214.32
}

Для цитирования: Шушпанова О.В. Применение антидепрессантов в комплексной терапии у больных раком молочной железы. Сибирский вестник психиатрии $и$ наркологии. 2021; 1 (110): 19-30. https://doi.org/10.26617/1810-3111-2021-1(110)-19-30

\section{Применение антидепрессантов в комплексной терапии у больных раком молочной железы}

\section{Шушпанова О.В.}

Научный иееттр психического здоровья

Россия, 115522, Москва, Каширское шоссе, 34

\section{PEЗЮME}

Проблема психического здоровья и субъективного восприятия (перцепции) качества жизни онкологических больных в настоящее время особенно актуальна. Большинство больных раком молочной железы (РМЖ) в процессе адаптации к заболеванию испытывают определенные нарушения в психической сфере: депрессивные, тревожно-фобические и психосоматические расстройства. Цель: изучение выраженности в клинической картине заболевания тревожно-депрессивных тенденций и оценка эффективности психофармакотерапии с применением антидепрессантов у больных раком молочной железы с выявленными расстройствами тревожно-депрессивного спектра. Материал и методы. Исследование включало 30 пациенток с впервые установленным (в среднем 6,8 $\pm 1,2$ месяца с момента диагностики) диагнозом РМЖ и 52 пациентки с длительностью катамнеза 3-17 лет. Основные методы: клинико-психопатологический и клиникодинамический. Психопатологическая оценка проводилась в рамках клинических разборов с привлечением междисциплинарного подхода. Для оценки выраженности в клинической картине тревожно-депрессивного синдрома и эффективности лечения использовались специальные стандартные шкалы: госпитальная шкала тревоги и депрессии (HADS), шкала общего клинического впечатления (CGI) для оценки тяжести заболевания (CGI-S «тяжесть») и улучшения психического состояния (CGI-I «улучшение»). Для оценки эффективности психофармакотерапии психометрические данные были обработаны статистически на базе программы Statistica 10 (метод с использованием критерия Хи-квадрат). Результаты. Получены высокие показатели эффективности терапии антидепрессантами в комбинации с препаратами бензодиазепинового ряда и гипнотиками в группе больных с тревожно-депрессивной нозогенией (88\% респондеров с редукцией стартовых баллов тревоги и депрессии по шкале HADS более 50\%, по шкале CGI 85\%), в группе пациентов с хронической ипохондрической дистимией и циклотимической эндоформной депрессией (соответственно 93,7\% и 90,6\%). Полученные в проведенном исследовании данные подтверждают эффективность психофармакотерапии антидепрессантами у больных РМЖ с выявленными расстройствами тревожно-депрессивного спектра. Заключение. Представленные клинические результаты могут в значительной степени способствовать в создании новых форм оптимизации психиатрической и психологической помощи онкологическим пациентам на лечебнодиагностическом этапе в условиях онкологического стационара.

Ключевые слова: рак молочной железы, распространенность в структуре онкологических заболеваний, тревожно-депрессивное расстройство у женщин, фармакотерапия, антидепрессивная терапия

\section{ОСНОВНЫЕ ПОЛОЖЕНИЯ ПРОБЛЕМЫ}

Изучение результатов терапии психических расстройств у онкологических пациентов показало эффективность применения психотропных средств. Контингент больных, обнаруживающих потребность в терапии психотропными средствами, варьирует, по разным оценкам, от $15 \%$ до $62 \%$. Антидепрессанты и нейролептики используются, согласно данным отечественных и зарубежных исследований, примерно от 10\% до $30 \%$ случаев. Мишени психофармакотерапии определяются синдромальной характеристикой пациента в соответствии со стандартными показаниями к применению психотропных средств [1, 2, 3]. Среди женщин трудоспособного возраста рак молочной железы (РМЖ) является одной из распространенных злокачественных опухолей $[2,3,4,5$, 6]. Большинство больных РМЖ в процессе адаптации к онкологическому заболеванию испытывают определенные нарушения в психической сфере: депрессивные, тревожно-фобические и психосоматические расстройства, посттравматический стресс, нарушения сна $[7,8,9,10,11$, $12,13,14]$. 
Психические расстройства при РМЖ в основном квалифицируются в рамках пограничных нарушений: тревожные и депрессивные расстройства различной степени тяжести, расстройство адаптации, посттравматическое стрессовое расстройство (ПТСР), дистимии, большое депрессивное расстройство $[11,12,13,14,15]$. Круг аффективных расстройств дополняют соматореактивная циклотимия $[16,17]$ и соматоформные расстройства $[12,18]$. Отмечено, что депрессивная симптоматика является превалирующей у пациентов с РМЖ $[19,20]$.

Клиническая картина аффективных и тревожных расстройств у больных РМЖ имеет сходство с эндогеноморфными депрессивными состояниями, характеризующимися длительными и сложными по синдромальной структуре депрессивными расстройствами, включающими, наряду с проявлениями гипотимии $[16,21]$, тревожнофобические и витальные расстройства $[21,22]$. Депрессия развивается у $15-25 \%$ онкологических пациентов, сопряжена с серьезными негативными последствиями, включая снижение качества жизни, ухудшение клинического прогноза онкологического заболевания и в конечном итоге сокращение длительности жизни $[23,24]$. У большинства больных перечисленные расстройства достигают клинического уровня. К наиболее частым симптомам авторы относят тревогу, повышенную утомляемость, раздражительность, нарушения сна, подавленность, чувство безнадежности, снижение аппетита, психомоторную заторможенность, потерю энергии, мысли о нежелании жить $[1,7,8,13,15]$.

Психофармакотерапия выявленных нарушений является обоснованным и последовательным звеном в структуре мероприятий по улучшению качества жизни и адаптации больных РМЖ [9, 10]. Клинически важный раздел опыта применения психофармакопрепаратов относится к антидепрессантам в терапии депрессивных расстройств и соматовегетативных симптомов у больных РМЖ [16]. По данным австралийских авторов [24], показатель распространенности назначения антидепрессантов для больных раком составлял $15,6 \%(95 \% \mathrm{CI}=13,3-18,3)$, для больных РМЖ - 22,6\% (95\% CI=16,0-30,9). Как считают отечественные авторы, популярными в применении антидепрессантами являются селективные ингибиторы обратного захвата серотонина (СИОЗС) $[16,17,18]$. Сибирскими исследователями описывается опыт применения антидепрессантов группы СИОЗС в терапии соматовегетативных расстройств у больных раком (астения, вазомоторные симптомы на фоне овариоэктомии либо антиэстрогенной терапии) $[17,18,19]$. В частности для терапии вазомоторных приливов жара пароксетин использовали в суточной дозировке 10 мг, флуоксетин 20 мг, циталопрам 10-20 мг, венлафаксин 37,5-75 мг [19]. Кроме того, эффективными в терапии вазомоторных расстройств являются сертралин в дозе 50 мг в течение 6-12 недель [20], дулоксетин 60 мг и эсциталопрам 20 мг в течение 12 недель [21]. Исследования показывают, что использование СИОЗС и ИОЗСиН (ингибиторы обратного захвата серотонина и норадреналина) значительно снижало частоту и тяжесть вазомоторных приливов у больных РМЖ в диапазоне от $14 \%$ до $58 \%$ по сравнению с плацебо [19].

Кроме того, описана эффективность антидепрессантов в комплексной терапии невропатических болей при РМЖ, включая тревожнофобические расстройства, большое депрессивное расстройство и ПТСР $[22,23,24,25,26,27,28,29$, 30]. Клинические исследования применения антидепрессантов разнообразны по показаниям к назначению и выбору препаратов. Амитриптилин назначался в качестве эффективного средства для купирования невропатической боли с увеличением суточной дозировки до 25-50 мг, снижал болевые ощущения у пациентов на 50\% [21]. Однако по сравнению с препаратами группы СОИЗС амитриптилин имел более выраженные антихолинергические побочные эффекты (19\%) [23]. Пароксетин в дозировке 20-40 мг/сут по сравнению с трициклическими антидепрессантами (ТЦА) является средством выбора для длительного применения [23, 24, 25, 26, 27]. СИОЗС являются препаратами первой линии для лечения тревожно-депрессивных расстройств у больных РМЖ вследствие хорошей переносимости терапии, в то время как трициклические антидепрессанты назначают с осторожностью и часто избегают в связи с высокой частотой побочных эффектов [28, 29, 30].

Назначение антидепрессантов группы СИОЗС следует соотносить с возможными перекрестными лекарственными взаимодействиями на уровне метаболизма системы цитохрома Р450 и его субъединицами CYP2D6 и CYP3A4, в особенности это касается больных РМЖ, принимающих тамоксифен и его аналоги $[31,32,33]$. Интересные данные были получены в совместной работе авторов из США и Франции [32] о лекарственных взаимодействиях наиболее популярных антидепрессантов (табл. 1).

Сертралин, эсциталопрам, циталопрам и венлафаксин характеризуются наименьшим перекрестным лекарственным взаимодействием и являются препаратами выбора при наличии расстройств депрессивного спектра у больных РМЖ. 
Т а б л и ц а 1. Цитохром Р450 опосредованные перекрестные лекарственные взаимодействия между антидепрессантами и препаратами антиэстрогенной терапии

\begin{tabular}{|c|c|c|c|}
\hline \multirow{8}{*}{$\begin{array}{c}\text { Селективные ингибиторы } \\
\text { обратного захвата } \\
\text { серотонина }\end{array}$} & \multirow{2}{*}{$\begin{array}{c}\text { Наименование } \\
\text { антидепрессанта }\end{array}$} & Тамоксифен & Торемифен \\
\hline & & CYP2D6 & CYP3A4 \\
\hline & Пароксетин & +++ & - \\
\hline & Флуоксетин & +++ & ++ \\
\hline & Сертралин & ++ & ++ \\
\hline & Циталопрам & + & - \\
\hline & Эсциталопрам & + & - \\
\hline & Флувоксамин & + & ++ \\
\hline Ингибиторы обратного захвата & Венлафаксин & + & - \\
\hline серотонина и норадреналина & Дезвенлафаксин & + & - \\
\hline (антидепрессанты двойного действия) & Дулоксетин & ++ & - \\
\hline & Амитриптилин & + & - \\
\hline & Нортриптилин & + & - \\
\hline Трициклические & Доксепин & + & - \\
\hline антидепрессанты & Дезипрамин & + & - \\
\hline & Имипрамин & + & - \\
\hline & Кломипрамин & ++ & - \\
\hline & Тимипрамин & - & - \\
\hline & Буспирон & - & - \\
\hline Другие препараты & Тразодон & - & - \\
\hline & Миртазапин & + & - \\
\hline & Бупропион & +++ & - \\
\hline
\end{tabular}

П р и м е ч а н и е: +++ - сильное ингибирование субъединиц цитохрома Р450, сильное перекрестное взаимодействие, ++ - среднее, умеренное ингибирование субъединиц, + - минимальное ингибирование субъединиц и перекрестное взаимодействие, - - отсутствуют перекрестные взаимодействия.

Такие препараты как сертралин, эсциталопрам, циталопрам и венлафаксин эффективны, хорошо переносятся, тем не менее необходима осторожность из-за возможности пролонгации интервала QT как при назначении высоких дозировок, так и у пациентов, принимающих аспирин, нестероидные противовоспалительные препараты, варфарин или гепарин [28].

Эффективность сертралина при всех видах депрессии у пациентов с РМЖ, проходящих химиотерапию, в дозировке 25-100 мг курсом 12 недель, подтверждается повышением показателей по шкале оценки депрессии Монтгомери-Асберга (MADRS) $>50 \%$ баллов в конечной точке исследования. Наблюдалось снижение усталости, ангедонии и суицидальных мыслей от начала исследования к его завершению [34].

Изучено применение эсциталопрама в дозе 10 мг курсом 2 недели у паллиативных больных раком, включая РМЖ, которые удовлетворяли критериям депрессивного расстройства по DSM-IV. Выраженность тревожно-депрессивных расстройств оценивали, используя шкалу тревоги и депрессии (HADS) и шкалу психической адаптации к раковой болезни (Mini-MAC). В конце исследования наблюдалось снижение тревожности, измеряемой шкалой HADS, и беспомощности, измеряемой шкалой Mini-MAC [35].
У больных раком описаны хорошая переносимость венлафаксина, минимальная активность в системе CYP450 и целесообразность назначения у больных, принимающих тамоксифен, из-за отсутствия ингибирования CYP2D6. Отмечена его способность понижать вазомоторные приливы у пациенток, получавших антиэстрогенную химиотерапию или перенесших овариоэктомию [36, 37].

Высокие показатели результативности терапии тревожно-депрессивных расстройств у пациентов с РМЖ показал флуоксетин. Пациенты с симптомами депрессии, выявленными путем двухэтапного скрининга, получали флуоксетин 20 мг/сут 6 месяцев. Выраженность депрессии оценивали по краткой шкале самооценки Zung (BZSDS). У $80 \%$ принимавших флуоксетин пациентов депрессивные симптомы редуцировались к концу исследования по сравнению с плацебо [37].

Дулоксетин является одним из ИОЗСиН для лечения депрессии и тревоги, невропатии и хронической боли у больных раком, в частности РМЖ $[39,40]$. У больных с РМЖ и с депрессией без онкозаболевания при использовании дулоксетина в дозе 30-60 мг по результатам исследований по трем шкалам: HADS, общего клинического впечатления (CGI-S) и оценки депрессии Монтгомери-Асберга (MADRS) обнаружено значительное улучшение показателей по каждой из шкал с 4-й по 12-ю неделю [39]. 
Отдельного внимания заслуживают антидепрессанты с мелатонинергическим эффектом. Показано, что риск развития депрессивных симптомов был значительно ниже в группе больных РМЖ, принимавших мелатонин, чем у пациентов из группы плацебо. Мелатонин значительно снижает риск депрессивных симптомов у женщин с РМЖ в 3-месячный период после операции и может использоваться в профилактических целях.

При стрессовых расстройствах, в частности ПТСР и тревожно-фобических расстройствах, препаратами выбора у онкобольных являются СИОЗС, ИОЗСиН и миртазапин в комбинации с бензодиазепинами [41, 42, 43, 44]. Миртазапин использовался для лечения большого депрессивного расстройства у больных раком, включая
РМЖ. У всех больных отмечался максимальный эффект со снижением количества баллов по шкале HAM-D с 21,4 в исходной точке до 2,6 после 6 месяцев терапии.

Миансерин обладал значительным антидепрессивным эффектом по сравнению с плацебо в терапии БДР у больных РМЖ I и II стадиями на протяжении 6 недель. К сожалению, клинические данные о терапии БДР у больных РМЖ немногочисленны. В основном речь идет о депрессии средней или легкой степени тяжести, выявляемой с помощью скрининга клиническими шкалами.

Таким образом, можно составить следующую схему целевого применения наиболее эффективных антидепрессантов по принципу «синдром назначение» (табл. 2).

\section{Т а б л и ц а 2. Наиболее часто назначаемые антидепрессанты и особенности их применения}

\begin{tabular}{|c|c|}
\hline Антидепрессант & Эффект \\
\hline $\begin{array}{l}\text { Амитриптилин } \\
\text { Кломипрамин } \\
\text { Имипрамин }\end{array}$ & $\begin{array}{c}\text { Седативный } \\
\text { Активирующий } \\
\text { Активирующий }\end{array}$ \\
\hline Флуоксетин & Терапия депрессивных и тревожных расстройств, ПТСР, вегетососудистых приливов жара \\
\hline Сертралин & Терапия депрессивных и тревожных расстройств, ПТСР, вегетососудистых приливов жара \\
\hline Пароксетин & $\begin{array}{l}\text { Терапия депрессивных и тревожных расстройств, ПТСР, вегетососудистых приливов жара. } \\
\text { Не рекомендуется больным, принимающим антиэстрогенную терапию (тамоксифен) }\end{array}$ \\
\hline Дулоксетин & $\begin{array}{l}\text { Терапия депрессивных и тревожных расстройств, ПТСР, вегетососудистых приливов жара, } \\
\text { хронической невропатической боли (совместно с габапентином) }\end{array}$ \\
\hline $\begin{array}{l}\text { Эсциталопрам } \\
\text { Циталопрам }\end{array}$ & Терапия депрессивных и тревожных расстройств, ПТСР, вегетососудистых приливов жара \\
\hline Венлафаксин & $\begin{array}{l}\text { Терапия депрессивных и тревожных расстройств, ПТСР, вегетососудистых приливов жара, } \\
\text { хронической невропатической боли (совместно с габапентином). Рекомендуется при приёме } \\
\text { тамоксифена }\end{array}$ \\
\hline Миртазапин & $\begin{array}{l}\text { Терапия депрессивных и тревожных расстройств, ПТСР, вегетососудистых приливов жара, } \\
\text { улучшает аппетит, снижает тошноту и рвоту, нормализует сон. Подходит пациентам, при- } \\
\text { нимающим тамоксифен }\end{array}$ \\
\hline $\begin{array}{l}\text { Мелатонин } \\
\text { Агомелатин }\end{array}$ & Депрессивные расстройства с нарушением сна. Рекомендуется при приёме тамоксифена \\
\hline
\end{tabular}

\section{ЦЕЛЬ ИССЛЕДОВАНИЯ}

Изучение выраженности в клинической картине заболевания проявлений тревожно-депрессивного синдрома и оценка эффективности психофармакотерапии с применением антидепрессантов в группе больных раком молочной железы с выявленными расстройствами тревожнодепрессивного спектра.

\section{МАТЕРИАЛЫ И МЕТОДЫ}

Исследование выполнено в отделении соматогенной психической патологии отдела по изучению пограничной психической патологии и психосоматических расстройств ФГБНУ НЦПЗ в сотрудничестве с отделениями химиотерапии и комбинированного лечения злокачественных опухолей и клинической фармакологии и химиотерапии, отделения химиотерапии, ФГБУ НМИЦ онкологии им. Н.Н. Блохина. Обследованы 82 пациентки с гистологически верифицированным
РМЖ. Из исследования исключались больные, состояние которых не позволяло выполнить клинико-психопатологическое обследование в необходимом объеме, а именно деменция (F00-F03), органический амнестический синдром, делирий, не обусловленный алкоголем или другими психоактивными веществами (F04-F05), расстройства личности и поведения вследствие болезни, повреждения и дисфункции головного мозга (F07), аффективные расстройства (F30.XX), метастатическое поражение менингеальных оболочек и головного мозга, психические расстройства и расстройства поведения, связанные с употреблением психоактивных веществ (F10-F19), ранее установленный диагноз «Шизофрения» (F20.XX), умственная отсталость (F70-F79), другие (кроме РМЖ) онкологические заболевания, другие клинически значимые тяжелые соматические заболевания. 
В исследование включались пациенты, соответствующие критериям: верифицированный диагноз «рак молочной железы», психопатологические расстройства, манифестирующие в связи с обстоятельствами соматического заболевания (F40-F48 невротические, связанные со стрессом, и соматоформные расстройства по МКБ-10).

В исследовании участвовали 30 больных с впервые установленным (в среднем 6,8 $\pm 1,2$ месяца с момента диагностики) диагнозом «рак молочной железы», поступивших в стационар для планового обследования и лечения (средний воз-

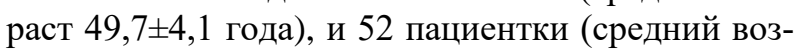

раст 56,8 46,7 года) с длительностью катамнеза 3-

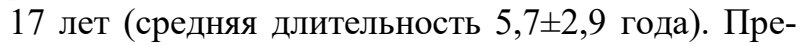
обладали больные с высшим образованием (50 $60,9 \%)$, состоящие в браке $(49-59,7 \%)$. Большинство пациентов не работали/находились на пенсии $(37-45,1 \%)$, около трети трудились со снижением профессиональной нагрузки (25 $30,5 \%)$, примерно четверть работали без снижения производственной нагрузки (20 -24,3\%).

Полученные данные о распределении больных выборки в зависимости от типа опухоли и методов химио- и лучевой терапии представлены в таблице 3.

\section{Т а б л и ц а 3. Характеристика исследовательской выборки больных по показателям онкологического заболевания (типу опухоли, стадии болезни, режиму химиотерапии)}

\begin{tabular}{|c|c|c|c|c|}
\hline Менструальный статус & \multicolumn{2}{|c|}{ Пременопауза } & \multicolumn{2}{|c|}{ Менопауза } \\
\hline Тип опухоли & $\begin{array}{l}\text { Гормоночув- } \\
\text { ствительные }\end{array}$ & \begin{tabular}{|l|} 
Гормоноре- \\
зистентные
\end{tabular} & \begin{tabular}{|l|} 
Гормоночув- \\
ствительные
\end{tabular} & $\begin{array}{l}\text { Гормоноре- } \\
\text { зистентные }\end{array}$ \\
\hline Стадия заболевания & II A - IV & I - IV & \begin{tabular}{|l|} 
I - II B \\
\end{tabular} & I - IV \\
\hline Кол-во больных (всего) & 18 & 49 & 3 & 12 \\
\hline Лучевая терапия & 1 & 2 & & \\
\hline $\begin{array}{l}\text { Гормонотерапия: } \\
\text { Антиэстрогены (тамоксифен, фульвестрант) } \\
\text { Ингибиторы ароматазы (летрозол, анастрозол, экземестан) }\end{array}$ & $\begin{array}{l}8 \\
7\end{array}$ & & $\begin{array}{l}2 \\
7\end{array}$ & \\
\hline $\begin{array}{ll} & \text { Режимы химиотерапии: }\end{array}$ & 1 & 6 & & 3 \\
\hline CA & 1 & 2 & & \\
\hline CVMF & & 2 & & \\
\hline Метотрексат +(A)ra-C & & & & 1 \\
\hline Таксаны + доксорубицин & & 2 & & 1 \\
\hline Таксаны + лапатиниб & & 2 & & \\
\hline Таксаны + гемцитабин & & 6 & & \\
\hline Таксаны +Pt & & 5 & & 1 \\
\hline Таксаны + винорельбин & & 4 & & \\
\hline Доксорубицин + Pt & & 2 & & 1 \\
\hline Винкристин + Pt & & 2 & & \\
\hline Гемцитабин + Pt & & 1 & & \\
\hline Этапозид + Pt & & & & \\
\hline Тастузумаб + капецитабин & & 2 & & \\
\hline Трастузумаб + доксорубицин & & & & 1 \\
\hline Трастузумаб + таксаны & & 3 & & 2 \\
\hline Трастузумаб + винорельбин & & 2 & & 1 \\
\hline Капецитабин + Pt & & 2 & & \\
\hline Капецитабин + таксаны & & 1 & & 1 \\
\hline Капецитабин + винорельбин & & 1 & & \\
\hline Капецитабин + доксорубицин & & & & \\
\hline Винорельбин + доксорубицин & & 1 & & \\
\hline Винорельбин + гемцитабин & & 1 & & \\
\hline
\end{tabular}

Основные методы исследования: клиникопсихопатологический и клинико-динамический. Клинико-психопатологическая оценка для уточнения психического статуса проводилась в рам- ках клинических разборов с участием сотрудников ФГБНУ «Научный центр психического здоровья» под руководством акад. РАН, проф. А.Б. Смулевича и д.м.н., проф. С.В. Иванова. 
Для оценки выраженности в клинической картине заболевания проявлений тревожнодепрессивного синдрома и эффективности лечения использовались стандартизованные психометрические шкалы: Госпитальная шкала тревоги и депрессии (HADS) [Zigmond A.S., Snaith R.P., 1983], шкала общего клинического впечатления (CGI) [Guy W., 1976] для оценки тяжести заболевания (CGI-S «тяжесть») и улучшения психического состояния (CGI-I «улучшение»). Для оценки эффективности психофармакотерапии психометрические данные статистически обработаны на базе Statistica 10 (метод с использованием критерия Хи-квадрат).

Выбор антидепрессантов для купирования расстройств тревожно-депрессивного спектра, подбор оптимальных доз и длительность курсов определялись индивидуально в зависимости от синдромальной структуры и в соответствии с динамикой психического и соматического статуса пациентов, а также с учетом потенциальных лекарственных взаимодействий в условиях полихимиотерапии [43[.

Возможные нежелательные перекрестные фармакологические эффекты оценивались по степени взаимодействия лекарственных препаратов с системой ферментов цитохрома Р450 (пароксетин не назначался больным, принимающим тамоксифен). Нежелательные побочные явления на психофармакотерапию отмечались в 5 случаях и выражались в тошноте, слабости, сонливости, головокружении. Эффективность терапии оценивалась дважды: через 6 недель лечения (непосредственный эффект) и через 12 недель (отдаленный эффект). Длительность психофармакотерапии варьировала от 3 до 18 месяцев. При досрочной отмене препаратов по каким-либо причинам (необходимость в хирургической операции, тяжелое соматическое состояние, участие пациентов в исследовании противоопухолевых средств по протоколу, самостоятельная отмена пациентом) отмечалось возобновление депрессивной и тревожной симптоматики в среднем чеpeз 2-5 дней после отмены. В случае прекращения терапии антидепрессантами спустя несколько месяцев (от 6 до 12) синдром отмены препарата не формировался. Переносимость психофармакотерапии была хорошей. Первые признаки регуляции психического состояния и клинического улучшения наступали на 10-14-й день антидепрессивной терапии и достигали максимального уровня к 6-12-й неделе лечения. В настоящем исследовании не зафиксировано случаев неблагоприятных лекарственных взаимодействий между психотропными средствами и препаратами, использующимися для химиотерапии рака молочной железы.

\section{РЕЗУЛЬТАТЫ И ОБСУЖДЕНИЕ}

\section{Показания к психофармакотерапии}

В группе пациентов с впервые диагностированным РМЖ (в среднем 6,8 1,2 месяца с момента диагностики) по данным клинического обследования и психометрических шкал тревожнодепрессивная нозогения зарегистрирована более чем у половины (17 из $30-56,6 \%)$ пациентов. Среднее количество баллов по госпитальной шкале HADS для этих больных составило: 18-20 - по шкале тревоги $(18,2 \pm 1,22), 16-20$ - по шкале депрессии $(17,93 \pm 1,38)$, что соответствует «выраженным нарушениям» (рис. 1).

По шкале клинического впечатления «CGI-S» средний суммарный балл составил 4,6 , что соответствует смещению показателя степени нарушений к значению «острые нарушения». В катамнестической группе больных с длительностью заболевания РМЖ 3-17 лет хроническая ипохондрическая дистимия, требующая медикаментозного воздействия, зарегистрирована у 23 больных, у 9 больных - циклотимическая эндоформная депрессия на фоне прогрессирования болезни после длительной (от 1 года до 7 лет) ремиссии РМЖ. В этой группе преобладали общая доля нуждающихся в психофармакотерапии больных (32 - 61,5\%). Среднее количество баллов по шкале HADS для этих больных составило: 14-16 - по шкале тревоги $(15,3 \pm 0,76), 16-18$ - по шкале депрессии $(17 \pm 0,79)$. Общий суммарный балл по шкале CGI-S составил 4,4, что соответствует среднему значению между «явными нарушениями» и «острыми нарушениями». В коррекции антидепрессантами нуждались большинство больных обеих групп (49 из $82-59,7 \%$ ).

Подбор психофармакопрепаратов и результаты терапии

Выбор антидепрессантов осуществлялся в зависимости от преобладания в клинической картине той или иной симптоматики: при тревожной симптоматике назначались средства с противотревожным и/или седативным эффектом, такие как пароксетин 10-40 мг/сут, миртазапин 15-45 мг/сут, амитриптилин 50-100 мг/сут. В случае преобладания тоскливого аффекта с признаками апатии рекомендовали приём препаратов с психостимулирующим (группы СИОЗС) и/или двойным действием (ИОЗСиН): сертралин до 100 мг/сут, венлафаксин до 150 мг/сут, дулоксетин до 120 мг/сут. С целью купирования тревожных и инсомнических расстройств к терапии антидепрессантами дополнительно назначались анксиолитические препараты (диазепам, алпразолам, клоназепам) либо гипнотики (зопиклон, золпидема тартат). Основные применяемые психотропные средства и их средние терапевтические дозировки указаны в таблице 4. 


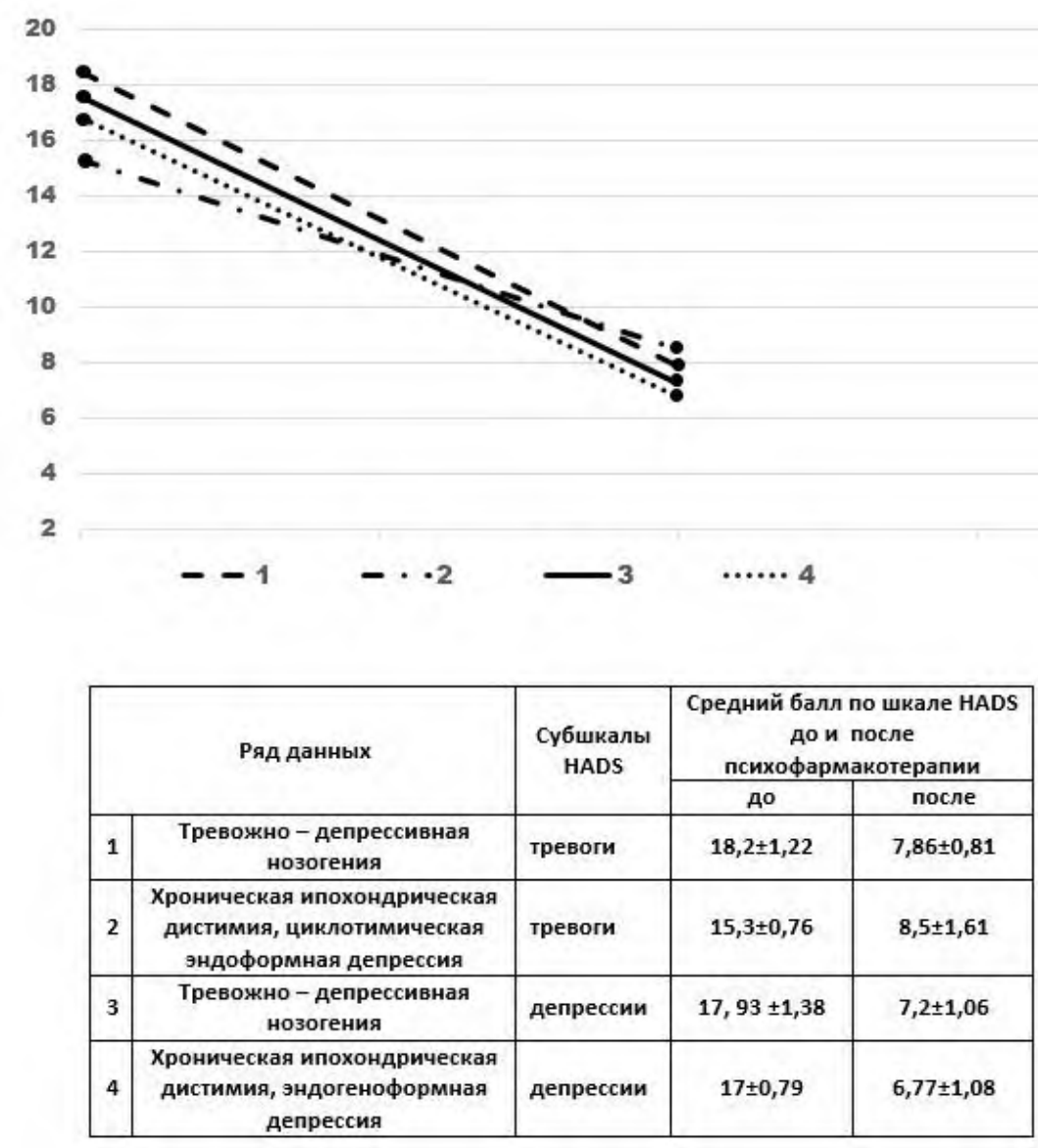

Р и с у н о к 1. Сравнительное распределение показателей средних баллов госпитальной шкалы тревоги и депрессии HADS до и после лечения у больных с тревожно-депрессивной нозогенией, хронической ипохондрической дистимией и циклотимической эндоформной депрессией

Т а б л и ц а 4. Суточные терапевтические дозировки психотропных средств

\begin{tabular}{|l|c|c|c|}
\hline \multicolumn{1}{|c|}{ Психотропные средства } & \multicolumn{3}{c|}{ Суточная доза препарата (мг) } \\
\hline Транквилизаторы & Мин & Макс & Средняя \\
\hline Производные бензодиазепина & & & \\
\hline Диазепам & 5 & 10 & - \\
\hline Лоразепам & 0,5 & 2,5 & 1,5 \\
\hline Клоназепам & 0,5 & 2 & 1 \\
\hline Феназепам & 0,5 & 2 & 1 \\
\hline Алпразолам & 0,5 & 1,5 & \\
\hline Производные других химических групп & & & 7,5 \\
\hline Золпидема тартрат & 5 & 10 & 5,75 \\
\hline Зопиклон Антидепрессанты & 3,75 & 7,5 & \\
\hline \multicolumn{1}{|c|}{ СИОЗС } & & & 100 \\
\hline Флувоксамин & & & 20 \\
\hline Пароксетин & 50 & 150 & 75 \\
\hline Сертралин & 10 & 40 & 75 \\
\hline Венлафаксин & 50 & 100 & - \\
\hline Дулоксетин & & & \\
\hline ТЦА (три, тетрациклические) & 50 & 100 & 45 \\
\hline Амитриптиллин & 60 & 120 & \\
\hline Миртазапин & 50 & & \\
\hline
\end{tabular}


У большинства пациентов с тревожнодепрессивной нозогенией наблюдался положительный эффект при терапии антидепрессантами через 7-10 дней - 88\% респондеров с редукцией стартовых баллов по клинической шкале HADS более $50 \%$ (7,86 $\pm 0,81$ по шкале тревоги и 7,2 $\pm 1,06$ по шкале депрессии, что соответствует субклиническому уровню), по шкале CGI 85\% (рис. 1).

Средний суммарный балл по шкале CGI-I (для оценки улучшения) на последнем визите составил 1,5 , что является средним значением между оценками 1 - очень выраженное улучшение и 2 - выраженное улучшение. Полная редукция тревожно-депрессивных расстройств отмечалась у 2 пациентов с начальными (I-II) стадиями РМЖ. В большинстве $(75 \%)$ случаев ощутимый терапевтический эффект развивался даже при назначении низких стартовых доз, не достигающих рекомендуемых значений по протоколу лечения.

В ряду признаков улучшения пациенты отмечали значительную редукцию тревожной симптоматики, нормализацию сна и аппетита, снижение подавленности, восстановление аффективного фона к 6-й неделе лечения. Стабилизация клинического эффекта наблюдалась к 12-й неделе психофармакотерапии. У 86\% пациентов сохранялись не достигающие клинического уровня фоновые проявления тревоги в силу особенностей диагноза и прогноза основного заболевания при последующем динамическом наблюдении. С целью закрепления достигнутой ремиссии в психическом состоянии больным проводилась поддерживающая терапия с частичным снижением дозировок (антидепрессанты) либо отменой (транквилизаторы) психотропных средств на протяжении 6-12 месяцев в зависимости от начальной степени тяжести и динамики тревожно-депрессивной симптоматики.

В катамнестической группе больных с хронической ипохондрической дистимией и циклотимической эндоформной депрессией установлена высокая эффективность психофармакотерапии. Доля пациентов с редукцией психопатологических симптомокомплексов (тревожно-фобические, астенические, соматоформные, аффективные расстройства, посткастрационная вегетативная симптоматика) более $50 \%$ по шкале HADS составила 93,7\%

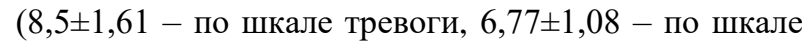
депрессии), а также со значительным клиническим улучшением по шкале CGI-I 90,6\% (средний суммарный балл равен 2). Значимый эффект от терапии связан с комбинированным применением психофармакопрепаратов высокопотенциальных бензодиазепинов и антидепрессантов группы СИОЗС, ИОЗСиН, три- и тетрациклических антидепрессантов. Клиническое улучшение наступало на 10-14-й день с дальнейшей постепенной редукцией тревожной и депрессивной симптоматики.
В 46\% случаев в клинической картине преобладали тревожно-фобические и соматоформные расстройства. Для их купирования использовались следующие психотропные препараты: алпразолам/ лоразепам 0,5-1 мг/сут, пароксетин 20-40 мг/сут, амитриптиллин 50-75 мг/сут, флувоксамин 50-100 мг/сут, миртазапин 15-45 мг/сут, сертралин до 100 мг/сут, венлафаксин до 150 мг/сут. У $53 \%$ пациентов преобладали аффективные и астенические нарушения. С целью их коррекции применялась эффективная терапия антидепрессантами группы ИОЗСиН: венлафаксин 75 мг/сут, дулоксетин 60 мг/сут. Для купирования сопутствующих инсомнических расстройств в обеих группах больных применялись препараты бензодиазепинового ряда (клоназепам, феназепам) либо гипнотики (золпидема тартрат, зопиклон). У $71 \%$ больных на фоне тревожнодепрессивного состояния усиливались соматовегетативные посткастрационные (климактерические) явления, связанные с применением антиэстрогенной гормонотерапии. Состояния гипоэстрогении, выражающиеся в вегетативной дисфункции (приливах жара, повышении артериального давления, приступах сердцебиения, головокружения, потливости) полностью либо значительно купировались на фоне приема сочетанной терапии антидепрессантами группы СИОЗС и противотревожных средств. В большинстве случаев клиническое улучшение наступало на 10-14-й день с дальнейшей постепенной редукцией тревожной и депрессивной симптоматики до субсиндромального уровня. Нормализовался аффективный фон, отмечалось улучшение качества сна и аппетита, дезактуализировались страхи, связанные с онкологическим заболеванием и ожиданием неблагоприятно-фатального исхода. При этом сохранялись явления симптоматической и реактивной лабильности (экзацербация психопатологических расстройств под влиянием соматогенных и психогенных факторов). В этих случаях рекомендовалось длительное применение минимальных доз используемых психотропных средств. Препараты и их дозы подбирались индивидуально с учетом переносимости и лекарственных взаимодействий, по принципу «соотношение пользы превосходит возможный риск для больного».

\section{ЗАКЛЮЧЕНИЕ}

Полученные в проведенном нами исследовании данные подтверждают эффективность психофармакотерапии антидепрессантами у больных РМЖ с диагностированными расстройствами тревожно-депрессивного спектра. В исследовании принимали участие две категории больных: как с впервые выявленным РМЖ, так и с длительностью катамнеза РМЖ 3-17 лет. Потребность в назначении психотропной терапии была установлена у пациентов с тревожно-депрессивной нозогенией, хронической ипохондрической дистимией и циклотимической эндоформной депрессией. 
Эффективность терапии антидепрессантами в комбинации с препаратами бензодиазепинового ряда и гипнотиками в группе больных с тревожно-депрессивной нозогенией показала высокий результат: $88 \%$ респондеров с редукцией стартового количества баллов тревоги и депрессии по HADS более 50\%, по шкале CGI 85\%. В группе больных с хронической ипохондрической дистимией и циклотимической эндоформной депрессией доля пациентов с полной редукцией психопатологических симптомокомплексов (тревожнофобические, астенические, соматовегетативные и аффективные расстройства) составила 93,7\% (по шкале CGI-I 90,6\%). Для пациентов с расстройствами тревожно-депрессивного, астенического и соматовегетативного спектра целесообразно назначение современных селективных серотонин- и норадренергических антидепрессантов, обладающих хорошей переносимостью и безопасностью (включая минимальный риск лекарственных взаимодействий). Для терапии указанных расстройств использовались средние терапевтические дозы с учетом сравнительно высокого уровня лечебного эффекта, установленного в ходе исследования. Финальные результаты нашего клинического исследования могут в значительной степени способствовать оптимизации психиатрической и психологической помощи онкологическим пациентам на лечебнодиагностическом этапе в условиях онкологического стационара.

\section{КОНФЛИКТ ИНТЕРЕСОВ}

Автор заявляет об отсутствии возможных конфликтов интересов в связи с публикацией материалов данной статьи.

\section{ИСТОЧНИК ФИНАНСИРОВАНИЯ}

Исследование выполнено за счет госбюджетного источника финансирования НИР ФГБНУ «Научный центр психического здоровья» (Москва).

\section{СООТВЕТСТВИЕ ПРИНЦИПАМ ЭТИКИ}

При проведении исследования соблюдены принципы информированного согласия Хельсинской декларации ВАМ.

\section{ЛИТЕРАТУРА/REFERENCES}

1. Агаркова Л.А., Куприянова И.Е., Балацкая Л.Н., Коломиец Л.А., Дикке Г.Б., Семке В.А., Марков А.А., Несмелова В.А. Сравнительные исследования качества жизни у женщин с доброкачественными и злокачественными опухолями гинекологической сферы. Сибирский онкологический журнал. 2004. № 1. С. 18-20. Agarkova LA, Kupriyanova IE, Balatskaya LN, Kolomiets LA, Dikke GB, Semke VA, Markov AA, Nesmelova VA. Comparative studies of the quality of life in women with benign and malignant gynecological tumors. Siberian Journal of Oncology. 2004; 1:1820 (in Russian).
2. Володин Б.Ю. Психосоматические взаимоотношения у онкологических больных. Паллиативная медицина и реабилитация. 2007. № 3. С. 5154. Volodin BYu. Psychosomatic relationships in cancer patients. Palliative Medicine and Rehabilitation. 2007;3: 51-54 (in Russian).

3. Галиуллина С.Д. Нервно-психические нарушения у больных раком молочной железы: автореферат дис. ... к.м.н. Уфа, 2000: 23 с. Galiullina SD. Neuropsychiatric disorders in patients with breast cancer: PhD thesis. Ufa, 2000:23 (in Russian).

4. Иванов П.М., Томский М.И., Мыреева С.А. и др. Злокачественные новообразования в Якутии (заболеваемость и смертность) / под ред. П.М. Иванова. Якутск : Сфера, 2018. 180 с. Ivanov PM, Tomskiy MI, Myreeva SA. et al. Malignant neoplasms in Yakutia (morbidity and mortality) / edited by P.M. Ivanov. Yakutsk: Sphere, 2018:180 (in Russian).

5. Нелюбина Л.А., Лактионов К.П. Причины заболевания раком молочной железы и возможности его профилактики. Вестник РОНЦ им. Н.Н. Блохина РАМН. 2013. № 24 (92). С. 3-10. Nelyubina LA, Laktionov KP. Causes of breast cancer and the possibility of its prevention. N.N. Blokhin ROSC RAMS Bulletin. 2013;24(92):3-10 (in Russian).

6. Пономарева Л.А., Сухарева У.А., Егорова А.Г., Сомов А.Н. Опыт реализации мер по снижению смертности от рака молочной железы. Онкология. Журнал им. П.А. Герцена. 2015. № 4 (6). C. 42-47. Ponomareva LA, Sukhareva UA, Egorova AG, Somov AN. Experience in implementing measures to reduce mortality from breast cancer. Oncology. P.A. Herzen Journal. 2015;4(6):42-47. (in Russian). doi: 10.17116/onkolog20154642-47

7. Самушия М.А., Зубова И.В. Нозогении (психогенные реакции) при раке молочной железы. Психические расстройства в общей медицине. 2009. № 1. C. 24-29. Samushia MA, Zubova IV. Nosogeny (psychogenic reactions) in breast cancer. Mental Disorders in General Medicine. 2009;1:2429 (in Russian).

8. Злокачественные новообразования в России в 2015 году (заболеваемость и смертность) / под ред. А.Д. Каприна, В.В. Старинского, Г.В. Петровой. М., 2017. 250 c. Malignant neoplasms in Russia in 2015 (morbidity and mortality) / edited by A.D. Kaprin, V.V. Starinsky, G.V. Petrova. Moscow, 2017:250 (in Russian).

9. Куприянова И.Е., Слонимская Е.М., Бехер О.А Нервно-психические расстройства у женщин, страдающих раком молочной железы. Психические расстройства в общей медицине. 2009. № 1 . C. 22-24. Kupriyanova IE, Slonimskaya EM, Bekher OA Neuropsychiatric disorders in women with breast cancer. Mental Disorders in General Medicine. 2009;16:22-24 (in Russian). 
10. Семке В.Я., Куприянова И.Е., Шушпанова Т.В. Психическое здоровье населения Сибири и Дальнего Востока. Журнал неврологии и психиатрии им. С.С. Корсакова. 2007. Т. 107, № 3. C.78. Semke VYa, Kupriyanova IE, Shushpanova TV. Mental health of Siberian and Far East populations. S.S. Korsakov Journal of Neurology and Psychiatry. 2007;107(3):78 (in Russian).

11. Тарабрина Н.В., Ворона О.А., Курчакова М.С., Падун М.А., Шаталова Н.Е. Онкопсихология: посттравматический стресс у больных раком молочной железы M., 2010. 175 с. Tarabrina NV, Vorona OA, Kurchakova MS, Padun MA, Shatalova NE. Oncopsychology: Post-Traumatic Stress in Patients with Breast Cancer. Moscow, 2010:175 (in Russian).

12. Шушпанова О.В. Психические нарушения у больных раком молочной железы: дифференцированный подход к изучению нозогений. Журнал неврологии и психиатрии им. С.С. Корсакова. 2017. T. 117, № 8. C. 18-26. Shushpanova OV. Mental disorders in patients with breast cancer: a differentiated approach to the study of nosogenies. S.S. Korsakov Journal of Neurology and Psychiatry. 2017;117(8):18-26 (in Russian). doi: 10.17116/jnevro20171178118-26

13. Sanjida S, Janda M, Kissane D, Shaw J, Pearson SA, DiSipio T, Couper J. A systematic review and meta-analysis of prescribing practices of antidepressants in cancer patients. Psychooncology. 2016 Sep;25(9):1002-16. doi: 10.1002/pon.4048

14. Butow P, Kelly S, Thewes B, Hruby G, Sharpe L, Beith J. Attentional bias and metacognitions in cancer survivors with high fear of cancer recurrence. Psychooncology. 2015 Apr;24(4):416-23. doi: 10.1002/pon.3659

15. Biglia N, Bounous VE, Susini T, Pecchio S, Sgro LG, Tuninetti V, Torta R. Duloxetine and escitalopram for hot flushes: efficacy and compliance in breast cancer survivors. Eur J Cancer Care (Engl). 2018 Jan;27(1). doi: 10.1111/ecc.12484

16. Roscoe JA, Morrow GR, Hickok JT, Mustian KM, Griggs JJ, Matteson SE, Bushunow P, Qazi R, Smith B. Effect of paroxetine hydrochloride (Paxil) on fatigue and depression in breast cancer patients receiving chemotherapy. Breast Cancer Res Treat. 2005 Feb;89(3):243-9. doi: 10.1007/s10549-0042175-1

17. Grassi L, Caruso R, Hammelef K, Nanni MG, Riba M. Efficacy and safety of pharmacotherapy in cancer-related psychiatric disorders across the trajectory of cancer care: a review. Int Rev Psychiatry. 2014 doi: 10.3109/09540261.2013.842542

18. Ersoy MA, Noyan AM, Elbi H. An open-label long-term naturalistic study of mirtazapine treatment for depression in cancer patients. Clin Drug Investig. doi: $10.2165 / 00044011-200828020-00005$
19. Baldwin DS, Anderson IM, Nutt DJ, Allgulander C, Bandelow B, den Boer JA, Christmas DM, Davies S, Fineberg N, Lidbetter N, Malizia A, McCrone P, Nabarro D, O'Neill C, Scott J, van der Wee N, Wittchen HU. Evidence-based pharmacological treatment of anxiety disorders, post-traumatic stress disorder and obsessive-compulsive disorder: a revision of the 2005 guidelines from the British Association for Psychopharmacology. J Psychopharmacol. 2014 May;28(5):403-39. doi: 10.1177/0269881114525674

20. Frampton JE, Plosker GL. Duloxetine: a review of its use in the treatment of major depressive disorder. CNS Drugs. 2007;21(7):581-609. doi: 10.2165/00023210-200721070-00004

21. Wedret JJ, Tu TG, Paul D, Rousseau C, Bonta A, Bota RG. Interactions between antidepressants, sleep aids and selected breast cancer therapy. Ment Illn. 2019 Jun 11;11(1):8115. doi: 10.4081/mi.2019.8115

22. Irarrázaval OME. Tamoxifeno y antidepresivos: Antagonistas en la prevención del cáncer de mama? [Antagonism of tamoxifen and antidepressants among women with breast cancer]. Rev Med Chil. 2011 Jan;139(1):89-99. Spanish. Epub 2011 Apr 11. PMID: 21526323

23. Yi JC, Syrjala KL. Anxiety and Depression in Cancer Survivors. Med Clin North Am. 2017 Nov;101(6):1099-1113. doi: 10.1016/j.mcna.2017.06.005

24. Kalso E, Tasmutha T, Pertti JN. Amitriptyline effectively relieves neuropathic pain following treatment of breast cancer. Pain. 1996 Feb;64(2):293302. doi: 10.1016/0304-3959(95)00138-7

25. Liebowitz MR, Gelenberg AJ, Munjack D. Venlafaxine extended release vs placebo and paroxetine in social anxiety disorder. Arch Gen Psychiatry. 2005 Feb;62(2):190-8. doi: 10.1001/archpsyc.62.2.190

26. L'Espérance S, Frenette S, Dionne A, Dionne JY; Comité de l'évolution des pratiques en oncologie (CEPO). Pharmacological and non-hormonal treatment of hot flashes in breast cancer survivors: CEPO review and recommendations. Support Care Cancer. $2013 \quad$ May;21(5):1461-74. doi: 10.1007/s00520-013-1732-8

27. Bringmann H, Singer S, Höckel M, Stolzenburg JU, Krauss O, Schwarz R. Longitudinal analysis of psychiatric morbidity in cancer patients. Onkologie. 2008 Jun;31(6):343-4. doi: 10.1159/000132166

28. Carvalho AF, Hyphantis T, Sales PM, Soeiro-deSouza MG, Macêdo DS, Cha DS, McIntyre RS, Pavlidis N. Major depressive disorder in breast cancer: a critical systematic review of pharmacological and psychotherapeutic clinical trials. Cancer Treat Rev. $2014 \quad$ Apr;40(3):349-55. doi: 10.1016/j.ctrv.2013.09.009

29. Medical Services Commission. Palliative care for the patient with incurable cancer or advanced disease. Part 2: Depression. Victoria (BC): British Columbia Medi- 
cal Services Commission. 2011. http: //www.bcguidelines.ca/pdf/palliative2_depression.pdf

30. Caraci F, Crupi R, Drago F, Spina E. Metabolic drug interactions between antidepressants and anticancer drugs: focus on selective serotonin reuptake inhibitors and hypericum extract. Curr Drug Metab. 2011 Jul;12(6):570-7. doi: $10.2174 / 138920011795713706$

31. Navari RM, Brenner MC, Wilson MN. Treatment of depressive symptoms in patients with early stage breast cancer undergoing adjuvant therapy. Breast Cancer Res Treat. 2008 Nov;112(1):197-201. doi: 10.1007/s10549-007-9841-Z

32. Schillani G, Capozzo MA, Era D, De Vanna M, Grassi L, Conte MA, Giraldi T. Pharmacogenetics of escitalopram and mental adaptation to cancer in palliative care: report of 18 cases. Tumori. 2011 May-Jun;97(3):358-61. doi: 10.1700/912.10034

33. Pezzella G, Moslinger-Gehmayr R, Contu A. Treatment of depression in patients with breast cancer: a comparison between paroxetine and amitriptyline. Breast Cancer Res Treat. 2001 Nov;70(1):110. doi: 10.1023/a:1012518831494

34. Chad-Friedman E, Coleman S, Traeger LN, Pirl WF, Goldman R, Atlas SJ, Park ER. Psychological distress associated with cancer screening: A systematic review. Cancer. 2017 Oct 15;123(20):38823894. doi: 10.1002/cncr.30904

35. Fulcher CD, Kim HJ, Smith PR, Sherner TL. Putting evidence into practice: evidence-based interventions for depression. Clin J Oncol Nurs. 2014;18 Suppl:26-37. doi: 10.1188/14.CJON.S3.26-37

36. Kimmick GG, Lovato J, McQuellon R, Robinson E, Muss HB. Randomized, double-blind, placebocontrolled, crossover study of sertraline (Zoloft) for the treatment of hot flashes in women with early stage breast cancer taking tamoxifen. Breast J. 2006 Mar-Apr;12(2):114-22. doi: 10.1111/j.1075122X.2006.00218.X
37. Rustad JK, David D, Currier MB. Cancer and posttraumatic stress disorder: diagnosis, pathogenesis and treatment considerations. Palliat Support Care. 2012 doi: $10.1017 / \mathrm{S} 1478951511000897$

Sep;10(3):213-23.

38. Spiegel D, Riba MB. Managing anxiety and depression during treatment. Breast J. 2015 JanFeb;21(1):97-103. doi: 10.1111/tbj.12355

39. Kang JI, Sung NY, Park SJ, Lee CG, Lee BO. The epidemiology of psychiatric disorders among women with breast cancer in South Korea: analysis of national registry data. Psychooncology. 2014 Jan;23(1):35-9. doi: 10.1002/pon.3369

40. Wiśniewska I, Jochymek B, Lenart-Lipińska M, Chabowski M. The pharmacological and hormonal therapy of hot flushes in breast cancer survivors. Breast Cancer. 2016 Mar;23(2):178-82. doi: 10.1007/s12282-015-0655-2

41. Grassi L, Nanni MG, Rodin G, Li M, Caruso R. The use of antidepressants in oncology: a review and practical tips for oncologists. Ann Oncol. 2018 Jan 1;29(1):101-111. doi: 10.1093/annonc/mdx526

42. Torta R, Siri I, Caldera P. Sertraline effectiveness and safety in depressed oncological patients. Support Care Cancer. 2008 Jan;16(1):83-91. doi: 10.1007/s00520-007-0269-0

43. Torta R, Leombruni P, Borio R, Castelli L. Duloxetine for the treatment of mood disorder in cancer patients: a 12-week case-control clinical trial. Hum Psychopharmacol. 2011 Jun-Jul;26(4-5):291-9. doi: 10.1002/hup.1202

44. Ramaswami R, Villarreal MD, Pitta DM, Carpenter JS, Stebbing J, Kalesan B. Venlafaxine in management of hot flashes in women with breast cancer: a systematic review and meta-analysis. Breast Cancer Res Treat. 2015 Jul;152(2):231-7. doi: $10.1007 / \mathrm{s} 10549-015-3465-5$

Поступила в редакцию 09.12.2020 Утверждена к печати 03.03.2021

Шушпанова Ольга Владимировна - научный сотрудник отдела исследования проблем детской психиатрии, ФГБНУ НЦПЗ (Научный центр психического здоровья).

SPIN-code 8979-9700. Researcher ID S-3346-2016. ORCID iD 0000-0003-3484-3447.

Шушпанова Ольга Владимировна, sertraline@list.ru 
For citation: Shushpanova O.V. The use of antidepressants in the complex therapy of patients with breast cancer. Siberian Herald of Psychiatry and Addiction Psychiatry. 2021; 1 (110): 19-30. https://doi.org/10.26617/1810-31112021-1(110)-19-30

\section{The use of antidepressants in the complex therapy of patients with breast cancer}

\section{Shushpanova O.V.}

Mental Health Research Center, Russian Academy of Sciences

Kashirskoe Highway 34, 115522, Moscow, Russian Federation

\section{ABSTRACT}

The problem of mental health and subjective perception of quality of life by cancer patients is currently specifically relevant. Most patients with breast cancer (BC) in the process of adaptation to their disease experience some mental disorders: depressive, anxiety-phobic and psychosomatic disorders. Objective: to study the severity of anxietydepressive tendencies in the clinical picture of the disease and to evaluate the effectiveness of psychopharmacotherapy with the use of antidepressants in breast cancer patients with identified disorders of the anxiety-depressive spectrum. Material and Methods. The study included 30 patients with newly diagnosed breast cancer (on average $6.8 \pm 1.2$ months from the date of diagnosis) and 52 patients with a follow-up period of 3-17 years. Basic methods: clinical-psychopathological and clinical-dynamic. The psycho-pathological assessment was carried out in the framework of clinical analyzes using an interdisciplinary approach. To assess the severity of anxiety-depressive syndrome in the clinical picture and the effectiveness of treatment, special standard scales were used: hospital anxiety and depression scale (HADS), clinical global impression scale (CGI) for assessing the severity of the disease (CGI-S "severity") and improvement of mental state (CGI-I "improvement"). To assess the effectiveness of psychopharmacotherapy, psychometric data were processed statistically using the Statistica 10 program (method using the Chi-square test). Results. High rates of effectiveness of antidepressant therapy in combination with benzodiazepine drugs and hypnotics were obtained in the group of patients with anxiety-depressive nosogeny ( $88 \%$ of responders with a reduction in the starting points of anxiety and depression on the HADS scale more than 50\%, on the CGI scale 85\%), in the group of patients with chronic hypochondriac dysthymia and cyclothymic endoform depression (respectively $93.7 \%$ and 90.6\%). The data obtained in this study confirm the effectiveness of psychopharmacotherapy with antidepressants in breast cancer patients with identified disorders of the anxiety-depressive spectrum. Conclusion. The presented clinical results can significantly contribute to the creation of new forms of optimization of psychiatric and psychological care for cancer patients when treating and diagnosing in an oncological hospital.

Keywords: breast cancer, prevalence in the structure of oncological diseases, anxiety-depressive disorder in women.

Received December 09.2020

Accepted March 03.2021

Shushpanova Olga V. - Researcher, Department for the Study of Problems of Child Psychiatry, Mental Health Research Center, Moscow, Russia.

SPIN-code 8979-9700. Researcher ID S-3346-2016. ORCID iD 0000-0003-3484-3447.

Shushpanova Olga V., sertraline@list.ru 